\title{
JOSÉ MARÍA QUIROGA PLÁ, POETA NEOCLÁSICO
}

Nuestra intención no es presentar la figura ni la obra de Quiroga Plá, tarea ya hecha por Francisco Ynduráin ${ }^{1}$ y, más recientemente, por Pascual Gálvez Ramírez ${ }^{2}$, sino analizar sobre todo la estética de los dos libros que el autor entregó a los lectores. Unos lectores, desde luego, escasos a juzgar por el colofón del primero, Morir al día, impreso en París en enero de 1946 e ilustrado con un retrato del autor por Joan Rebull: "La edición original en papel de Auvernia fabricado a mano, consta de 100

1 F. Ynduráın, “Apuntes sobre el poeta José María Quiroga Plá (19021955)", en Homenaje a la memoria de don Antonio Rodríguez-Moñino, 1910-1970, Castalia, Madrid, 1975, pp. 623-635.

2 Véanse de Pascual Gálvez Ramírez, "José María Quiroga Plá: una fábrica de realidad ignorada”, en M. Aznar, N. Dennis y B. Sicot (eds.), Exils et migrations ibériques au Xx ${ }^{e}$ siècle, 6 (1999), pp. 79-93; "José María Quiroga Plá: la poesía entre el concepto y la vida”, en R. Douroux y B. Sicot (eds.), Exils et migrations ibériques au $X^{e}$ siècle, 8 (2000), pp. 71-86; "La poesía producida por los exiliados en Francia: Rafael Alberti, José María Quiroga Plá y Jacinto Luis Guereña”, Las literaturas del exilio republicano de 1939. Actas del II Congreso Internacional, ed. Manuel Aznar Soler, GEXEL, San Cugat del Vallés, 2000, t. 1, pp. 491-507; "La poesía de José María Quiroga Plá: una realidad reflejada en el espejo desazogado de la historia de la literatura”, Laberintos, Valencia, 13 (2011), pp. 179-209; de Juana María González García, Pascual Gálvez Ramírez y Mario Pedrazuela Fuentes, "Epistolario Pedro Salinas-José María Quiroga Plá: una amistad en dos tiempos", Laberintos, Valencia, 16 (2014), pp. 349-380. Véase también nuestro artículo "La realidad reflejada por José María Quiroga Plá", en Homenaje a Bernard Sicot, Université Paris $\mathrm{X}$-Nanterre, Paris, en prensa. 
ejemplares numerados de 1 a 100"3. Puesto que el segundo se imprimió en México en 1955, año de la muerte de Quiroga, en tirada de mil ${ }^{4}$, cabe decir que su obra poética fue muy minoritaria, ya que no pieza de bibliófilo, en cualquier país. El espejo desigualmente azogado a que alude P. Gálvez, jugando con títulos del poeta, no es, pues, el único responsable. Más bien habrá que postular que Quiroga no hizo grandes esfuerzos por llegar al público, sino que tras la Guerra vivió al margen de la literatura de sus colegas en la Península o en el exilio, entregado a sus labores y ensimismado en sus vivencias. Sea o no exacta esta apreciación, como poeta, Quiroga Plá es un neoclásico, tanto o más que lo había sido su suegro Unamuno, o que lo fueron, tras la Guerra Civil, Gerardo Diego, Juan José Domenchina o Rafael Alberti. Definir a alguien como neoclásico resulta fácil, y habitualmente supone una valoración negativa. No obstante, el neoclasicismo es algo tan común en el arte del siglo xx, que, para Tomás Marco, la práctica totalidad de la música de nuestro tiempo fue, o acabó por ser, neoclásica, sobre todo la fundada en la "poética artesana", o dominio del oficio ${ }^{5}$. Algo de lo que, según el mismo autor, tampoco estuvieron libres la mayoría de los escritores o pintores, ni siquiera Picasso.

Como bien señala Marco, el neoclasicismo no es necesariamente sinónimo de conservadurismo, aunque también puede usarse como escudo protector contra las novedades, y entonces sí es una tendencia reaccionaria (p. 119). A nuestro juicio, lo difícil es no caer en el neoclasicismo y cultivar la revolución permanente. Una actitud ni posible ni deseable, porque el arte no consiste en buscar siempre nuevos territorios, sino también en

${ }^{3}$ Lo que a YNDURÁIn, amigo de Quiroga, le parece "pobre papel y tosca presentación" en el libro Morir al día (art. cit., p. 626), a otros se nos antoja edición de lujo, y más en aquellos años. El papel de Auvernia se sigue haciendo a mano en el Moulin Richard le Bas, en Ambert d'Auvergne, que data del siglo xv; entre otras cosas se usa para los diplomas del Premio Nobel. Sobre el molino y su actividad, si no recordamos mal, escribió una hermosa página Paul Valéry.

${ }^{4}$ Dato que agradecemos a Tomás Granados y Rosario Martínez, del Fondo de Cultura Económica de México. Según Gálvez, en la publicación del libro intervinieron Max Aub y Joaquín Díez-Canedo.

5 Tomás Marco, Pensamiento musical y siglo xx, Fundación Autor, Madrid, 2002, en especial el capítulo 3, "El fenómeno del neoclasicismo", donde se encuentra esta afirmación: "Acabado el siglo, toda la etapa puede verse a la luz de un neoclasicismo del que casi nadie escapó, y que no solo consolidó la primera vanguardia sino que también la hizo evolucionar" (p. 118). 
recorrer los ya conocidos descubriendo en ellos efectos insospechados. Si nada hay más obsoleto que el periódico de la víspera, pocas cosas de la vanguardia siguen produciendo un siglo después la impresión juvenil y rompedora que pudieron dar en el momento de su eclosión. Entre ellas quizá más que ninguna han envejecido las innovaciones métricas, como el vers libre, en el que ya Eliot supo percibir muy pronto cuánto podía haber de mala prosa ${ }^{6}$, y al que más tarde Louis Aragon acusaría de haber usurpado el nombre de libertad ${ }^{7}$. Por otra parte, si continuar cualquier línea ya trazada es neoclasicismo, tan neoclásico será imitar el soneto de Petrarca como el verso libre de Jaimes Freyre o la verborrea surrealista, la única diferencia estriba en seguir a un padre, a un abuelo o a un rebisabuelo, ya que renunciar a toda herencia no está al alcance de nadie. En la frase "lo que no es tradición es plagio", el plagio significa solo una forma torpe de inscribirse en una tradición que no se puede ignorar.

Quiroga Plá -que con el tiempo será yerno y secretario de Unamuno, crítico, narrador y traductor- se estrena a los 16 o 17 años: su poema "Motivos del Ultra. (Músicas en la noche)" vio la luz en Grecia, núm. 12 (Sevilla, 1 de abril de 1919), p. 10, lo que acredita una temprana inquietud estética ${ }^{8}$. Entre ese poema y las "Baladas para acordeón", sin duda hubo otras primicias, pero están sin localizar. La "Balada del viajero. (A Jorge Guillén)", se publicó en el Suplemento Literario de "La Verdad" (Murcia), núm. 54 (20 de junio de 1926). "Delgadina" aparece en Litoral, 2 (diciembre de 1926). Otras dos, "Caracol" y "Diana de aventura”, en la Revista de Occidente, 18 (1927), las últimas dedicadas a Pedro Caravia [Hevia], asturiano, profesor de Filosofía (1902-1984). "Don Bueso" y de nuevo "Diana de aventura", salieron en Litoral, 5/7 (octubre de 1927, homenaje a don Luis de Góngora), esta con pequeños cambios. En alguna de ellas

6 "No existe una división entre verso conservador y vers libre, porque solo hay versos buenos, versos malos y el caos" (T. S. ELIOT, Criticar al crítico y otros escritos, trad. de M. Rivas Corral, Alianza, Madrid, 1967, p. 252). Poco antes había dicho esto: "Si el vers libre fuera una forma auténtica de versificación, tendría una definición positiva. Y solo puedo definirlo por cualidades negativas: 1) carencia de estructura formal; 2) carencia de rima; 3) carencia de metro" (p. 245). Las "Reflections on Vers Libre" son de 1917.

7 "La rime en 1940", apéndice a Le crève-coeur, Gallimard, Paris, 1946, p. 76. En la misma página se refiere a "la poésie logorrhéique de ces dernières années".

${ }^{8}$ El poema está en verso libre y sus motivos, a pesar del título, son más románticos que ultraístas. 
se puede detectar cierta influencia de García Lorca, que había publicado tres romances en el primer número de la revista (noviembre de 1926). Por último, en Meseta, 4 (abril de 1928), apareció un "Gerineldo", cuya peculiaridad veremos luego. Quiroga recrea escenas de los romances de Delgadina y Gerineldo; en cambio, apenas alude a don Bueso, de quien solo se conservan romances tardíos, más bien burlescos ${ }^{9}$.

Son interesantes las licencias métricas que presentan algunos de estos romances. El de "Delgadina" inserta versos de 6, 7 o 9 sílabas entre sus octosílabos. También "Caracol”, de asonancia $a ́-e$, una vez la cambia en $a ́-a$ ("escarolado de nácar"), y tres en asonancia aguda -á ("anclada en mi soledad", "tiembla, en alga y plata, el mar", "esa afanosa espiral”). Esta anomalía, en cuanto a la estética del poeta, puede ponerse en relación con otras: el romance "Kilométrico" (Verso y Prosa, 9, septiembre de 1927), de asonancia $a-a$, la suspende en dos de sus versos, mientras que los del mismo grupo, "Bailadora" y "Acuarium", son regulares. El "Telegrama de madrugada", aparecido en Carmen, 6/7 (junio de 1928), en vv. 11-12 salta la asonancia á-e, que se reanuda en el 13, y la deja ya hasta el final asentada en los impares. Algo similar sucede en "Media voz" (Ddooss, 3, marzo de 1931, p. 1), donde la suspensión se repite, y en el primero de los cinco poemas reunidos bajo el título "Alta tensión" (Revista de Occidente, 36, 1932, pp. 301-303), otro romance regular excepto en vv. 51-52, que suprimen la asonancia (é-a), recuperada en el 53, y mantenida también hasta el final en los impares. El caso más llamativo es el de "Gerineldo" (término que en el cuerpo del poema aparece siempre como Genireldo). Se trata de un romance anómalo desde el primer verso, recorrido por la asonancia é-o, pero que otorga otras a los demás versos, sin dejar ninguno libre. El poeta, según se ve, oscila entre la atracción por la forma y el escaso respeto por su preceptiva. Un respeto, sin embargo, total en el caso del poema "Salamanca. (Academias)", muy en la línea de Unamuno, que consta de 14 liras de 5 (Verso y Prosa, 7, julio de 1927), y en la "Oda a Salinas", compuesta también en liras (Carmen, 3-4, marzo de 1928), al igual que la "Soledad" de

9 Un romance de Delgadina ("El buen rey tenía tres hijas / muy hermosas y galanas") lo transcribe Menéndez Pelayo en el volumen de Apéndices y suplemento a la Primavera y flor de romances, de Wolf y Hoffmann, donde también hay varios de don Bueso y Gerineldo. Quiroga conoció los de Delgadina y Gerineldo incluidos por Menéndez Pidal en su Flor nueva de romances viejos (1928), libro que reseñó en la ROcc, 64 (1928), pp. 106-112. 
García Lorca que la precede en el mismo número, "ofrenda" a fray Luis de León. Tan importante como la métrica es en este caso el contenido. El poeta, aunque desde el título parece invocar al músico amigo de fray Luis, en realidad se dirige al poeta Pedro Salinas en estos términos: "Mira que, si no nuevo / verso, sí nueva voz traigo a tu oído", una declaración estética que se completa con el ruego de las estrofas finales:
Piloto sé, y hermano,
A esta mano de ciego que encomiendo
$\mathrm{Al}$ calor de tu mano
En tanto que desvendo
Mis ojos, y a tu oído mi voz tiendo;
Porque no he de volverme
A la mar si tu mano no me guía
A la isla en que duerme,
Desnuda -al tacto, fría;
Por dentro, brasa-, en perla, la poesía.

Comentando la oda a Salinas de fray Luis dice Antonio Alatorre: "No les queda mal a estas diez liras el título de Oda a la música" 10 . Lo mismo viene a ser la de Quiroga, siempre que por música entendamos un valor amplio capaz de abarcar la poesía del agustino, pues no es música precisamente lo que destaca en la de Pedro Salinas, quien para esas fechas solo había publicado Presagios (1923) y un insulso libro de relatos, Víspera del gozo (1926), aludido en un verso de Quiroga. En otro lugar hemos notado la escasa iconoclastia de los poetas de aquel grupo que, cultivando los desplantes vanguardistas (como los de Gerardo Diego), eran capaces de celebrar a fray Luis y a Góngora en sus centenarios, sin perder de vista a otros clásicos, tal como hizo Altolaguirre en sus publicaciones ${ }^{11}$. El mismo núm. 1 de Los Cuatro Vientos (febrero de 1933), donde Quiroga Plá se acerca al lenguaje surrealista y que se abre con la "Oda al rey de Harlem" de García Lorca, incluye el ditirambo de Cernuda a Juan Ramón Jiménez, y cinco sonetos de Diego bajo la rúbrica "Romanticismo", tres de ellos dedicados a Beethoven, Schu-

10 Fray Luis de León, Nueve odas (y algo más), ed. Antonio Alatorre, Universidad Autónoma Metropolitana, México, 1999, p. 11.

11 A. CARreira, "Manuel Altolaguirre, editor de los clásicos", en Viaje a las Islas invitadas. Manuel Altolaguirre (1905-1959), ed. James Valender, Residencia de Estudiantes, Madrid, 2005, pp. 523-551. 
bert y Schumann, de quienes nada se conmemoraba ese año. El poema de Quiroga, "Puertas y arrabal del sueño", está dividido en cinco partes, todas en ritmo endecasilábico excepto la tercera, que adopta el verso libre, forma en la que el poeta no parece sentirse cómodo, a pesar de lo cual ese texto es la sección menos hermética del conjunto.

De las páginas críticas de Quiroga nos fijaremos en la titulada "Ulises adolescente" sobre los primeros libros de Alberti ${ }^{12}$. Es elogiosa, pero leída entre líneas, desde el mismo título deja entrever ciertos reparos a una poesía, en el mejor de los casos, más hábil que auténtica. En ella destaca "piezas deliberadamente convencionales: el marinero, la sirenilla", "un grado de perfección pasmoso" que "tenía que llevar aparejado, fatalmente, el amaneramiento" (pp. 404-405). Señala "la parte más endeble de su obra: las cancioncillas, las nanas, cuanto pudiera atarle demasiado a una puerilidad afectada, de receta" (p. 405), de la que se habría desprendido Cal y canto. Tan pronto habla de "poesía, noblemente decorativa", de "pirotecnia lírica", como advierte "el mismo aire de verbena, la misma arbitrariedad traviesa y sonriente" de las estampas de Maruja Mallo (p. 406), pintora a quien Quiroga estudió en dos números de Mediodía (XII y XIII). A continuación viene el párrafo de mayor interés, por lo que supone de reflexión sobre la propia estética:

Lo que ha llevado a los mejores de nuestros poetas, al salir de la anarquía provisional -y necesaria- del ultraísmo y de otros "ismos", hacia la estrofa, hacia la voluntaria sumisión a las normas preceptivas, ha sido - prescindiendo de otras razones, y por paradójica que resulte la afirmación- ni más ni menos que la inaplazable necesidad de crearse un orden propio, incanjeable. Sería erróneo ver, en ese retorno al romance, a la décima, al soneto, al terceto, etc., una ciega, absoluta vuelta de hijos pródigos a la tiranía (?) de la estrofa. De esta, en los casos que realmente cuentan, no han tomado los jóvenes poetas sino la geometría, con un sentido independiente y riguroso de la disciplina. Nada de alfarería neoclasicista; nada de virtuosismo, tampoco. Ejercicio, sí; un ejercicio gimnástico, si bien se mira. Pero el método, hallado y apartado por cada cual para sí mismo, con arreglo a sus propios medios (p. 407).

Declaración, si la entendemos bien, algo contradictoria. Por un lado, la anarquía de los "ismos" era "provisional y necesa-

12 ROcc, 23 (1929), pp. 403-408. 
ria”. Un sarampión que, una vez superado, permitió volver, fuese o no como hijos pródigos, a la estrofa, cuya "tiranía" lleva un expresivo interrogante. Por otro, esa vuelta no es "alfarería neoclasicista"; Quiroga prefiere verla como geometría, gimnasia y búsqueda de método. En el segundo artículo sobre la Mallo había dicho en tono de sentencia: "Tener forma no es otra cosa que significar" ${ }^{13}$. Una conclusión semejante a la que llegó Unamuno poco después, apelando también a la geometría:

\author{
Estrofa de cera \\ hexagonal, fría; \\ miel de ricas flores, \\ arte verdadera; \\ la geometría \\ hace a los cantores
}

$(26-V I I I-30)^{14}$.

Ahora, si se ponen las cosas en orden cronológico, veremos que no cuadran del todo con la trayectoria del propio Quiroga. En el Suplemento Literario de "La Verdad" (Murcia), núm. 59 (10 de octubre de 1926), publica el primer "Soneto a Sibila" -presumiblemente su esposa Salomé Unamuno-, y en Mediodía, 10 (julio de 1927), "Cinco sonetos a Sibila". En Meseta, 4 (abril de 1928), además del citado romance de Gerineldo, otros "Seis sonetos a Sibila". De la misma serie parece el que comienza "Sórdido navegante de este frío" (Héroe, 4, 1932). Los cuatro primeros son de métrica normal, los nueve restantes adoptan la forma de tres serventesios (uno de ellos cuarteto y dos serventesios) más pareado, habitual en la lírica inglesa. El poeta, dejando a un lado su etapa adolescente, comienza su carrera en 1926 con romances -en los que observamos leves anomalías, que siguen hasta 1931-, continúa con sonetos, bien medidos y rimados, y los alterna con poemas en perfectas liras de 5 , uno de los cuales se vuelve a fray Luis de León y a Salinas tomándolos como maestros. En el grupo “Alta tensión” (1932), del que hemos mencionado el romance inicial, hay otros cuatro poemas. El segundo (“¿Para qué, si no podré / Decírtelo...?”) es una composición octosilábica con tendencia a la asonancia en $i-a$, a ratos mutada o ausente. Conviene recordar sus ver-

13 Mediodía, 13 (octubre de 1928), p. 4.

14 Cancionero, poema 1538, ed. de F. de Onís, Losada, Buenos Aires, 1953, p. 420. 
sos finales: "Poesía, memorial / Inútil de cada día, / En que se sueña trocada / De niebla a forma mi vida" (p. 305). El tercero ("Todos los bosques del mundo") es asimismo octosilábico, pero en verso blanco, sin asonancia por ninguna parte. En él cabe destacar también unos versos metapoéticos, final de una larga frase:

Solo si el sueño nos lleva
Por la mano y de puntillas
Hasta sus inciertas hoyas
Para devolvernos luego,
Nublados de ansia los ojos,
A vagar de puerta en puerta,
De hermetismo en hermetismo,
Hechos balbucientes máscaras
De la estatua de ceniza
Que agoniza en nuestra entraña

(pp. 306-307).

El cuarto poema, en serventesios bien aconsonantados, es acaso el mejor, y, a pesar de los ecos de Shakespeare o Baudelaire, nunca suena a pastiche. He aquí su final: "Vivir, soñar, morir... Los tres espejos, / Nidos de hielo en que una misma nada / Trenzando letras de humo inventa, lejos, / A un mismo hastío diferente almohada" (pp. 308-309). El quinto, en 25 endecasílabos blancos, es un poema de amor. Ya hemos citado "Puertas y arrabal del sueño", publicado en 1933, año en que Quiroga enviuda ${ }^{15}$. Su rumbo ha sido, obviamente, mucho menos rectilíneo del marcado en el párrafo transcrito. Aquí la

15 Salomé de Unamuno, que llevaba cinco años a Quiroga, murió en Salamanca el 12 de julio de 1933. Su único hijo, Miguel (1929-2000), al estallar la guerra, quedó a cargo de su tía materna Felisa y luego estudió medicina. En los años treinta Quiroga había seguido alguna clase de Américo Castro en la Universidad de Madrid, aunque ignoramos qué título pudo obtener. IsABel García LoRCa lo recuerda en estos términos: "Nuestro gran amigo y defensor en aquella clase era el poeta Quiroga Plá, yerno de Unamuno, que se había matriculado aquel curso, aunque era mucho mayor que todos nosotros. Hombre ingenioso y culto, sabía mucho. Con él Castro no se atrevía. Sentía por mí una gran simpatía y yo por él, aunque nunca sostuvimos eso que se llama una conversación. Me decía: Ánimo, muy bien" ("Mis recuerdos de la Universidad de Madrid y del crucero por el Mediterráneo", en La Facultad de Filosofía y Letras de Madrid en la Segunda República, SECC, Madrid, 2008, p. 656). A fines de 1947 Quiroga se casó con su segunda esposa, Suzanne Duval, con quien vivió el resto de sus días. 
vuelta a la estrofa no se explica solo como reacción a la "anarquía" o necesidad de gimnasia, sino que también cabe admitir que el poeta escarmienta en cabeza ajena, por decirlo con la frase vulgar, sin sufrir él mismo la fiebre vanguardista. A nuestro parecer, más bien manifiesta desde muy pronto una tendencia al orden, a "cuadricular el sentimiento" -en palabras de Pascual Gálvez-, de la que solo escapa contadas veces a medida que la vanguardia se diluye.

Quiroga militó en Izquierda Republicana y, desde el comienzo de la Guerra Civil, en el Partido Comunista, hasta que lo abandonó en 1939 como protesta por el pacto germano-soviético. En su poesía no dejó huellas tal filiación política, y muy pocas la guerra misma: el romance de Doval (El Mono Azul, I, 7, 8 de octubre de 1936, p. 5, luego en el Romancero general de la guerra de España), el poema "Esperanza en pie" (Hora de Espa$\tilde{n} a$, núm. 17, mayo de 1938), y alguna vaga alusión en los dos publicados por la misma revista meses antes (núm. 12, diciembre de 1937). En cuanto a la métrica, si los tres últimos están en ritmo endecasilábico no siempre firme, pronto Quiroga optará por el soneto como vehículo preferido. Los seis que aún saca en el núm. 21 de Hora de España (septiembre de 1938) serán, con pocos cambios, los primeros de Morir al día, y van, como los demás del libro, cuidadosamente fechados. El poeta utiliza otros metros en los poemas que dio a conocer en el Boletín de la Unión de Intelectuales Españoles (BUIE), desde 1944 a 1948, pero aun ahí el soneto será la forma predominante. Ya dijimos que en los dos libros es exclusiva.

Los 150 sonetos de Morir al día se distribuyen así: 18 alejandrinos; 127 endecasílabos; 3 eneasílabos; 1 octosílabo y 1 hexasílabo. Los 126 de La realidad reflejada son todos sonetillos: 1 eneasílabo; 114 octosílabos; 2 heptasílabos y 9 hexasílabos. Con eso está dicho que Quiroga elige el soneto también como banco de pruebas. No habrá quizá en toda la literatura contemporánea poeta más fiel a esa forma métrica, y que más haya experimentado con ella. En ese sentido, le es aplicable la frase de otro gran sonetista, Juan José Domenchina: "Mi fe en la validez suficiente de los catorce versos es absoluta"16, y no menos la de su editora y estudiosa, Amelia de Paz: "la forma se le vuel-

${ }^{16}$ Prólogo a El extrañado (1958), Obra poética, ed. Amelia de Paz, Castalia, Madrid, 1995, t. 2, pp. 304-305. 
ve salvavidas" ${ }^{17}$. Ella misma calcula en un cuarto de millar los sonetos publicados por Domenchina, cifra muy próxima a la de Quiroga, y compuesta por las mismas fechas; la diferencia estriba en que el primero solo se aparta del endecasílabo en contadas ocasiones, y busca la rima pobre, aunque no escatima otros artificios. Quiroga conoció sin duda la obra poética y crítica de Domenchina, pero la media docena de poemarios que este publicó en México entre 1942 y 1952 difícilmente habrá llegado a su noticia. Tampoco es probable que haya leído los Sonetos de Torres Bodet (México, 1949), espléndido muestrario de 56 poemas donde no faltan algunas de las variantes más practicadas por Quiroga, entre ellas dos sonetos octosílabos y uno eneasílabo. Sea como fuere, le basta haber sido gran lector y especialista en literatura francesa en la época que trabajó para el Centro de Estudios Históricos, para estar al tanto de las novedades introducidas en el campo de la métrica, asunto que hubo de interesarle, puesto que en 1946, entre sus obras en preparación, anuncia un Tratado de versificación española.

Las metamorfosis del soneto comenzaron pronto. En la Italia del siglo Xvi hay ya sonetos con serventesios, de rima directa o inversa, obra de Iacopo Zane, Bernardo Tasso, Giovanni della Casa, Isabella Morra, Isabella Andreini o Giovan Battista Pigna. También cuartetos de rima inversa, de Barbara Torelli o Galeazzo di Tàrsia. Ambas fórmulas se multiplican en el siglo XVII, con ejemplos de Marino, Chiabrera y sus seguidores. En el siglo XIX el joven Carducci se entretuvo en añadirles largos estrambotes, como había hecho Berni en el siglo Xvi. Rengifo cita sonetos italianos "que lleuan los versos de a siete sýlabas, que llaman ellos Septenarios, o los que parte los lleuan de a siete y parte de onze"18. En Francia, Antoine de Baif fue el primer poeta que haya compuesto un soneto en alejandrinos, en 1552, y que usa cuatro rimas en los cuartetos, casi siempre abrazadas, en lo cual fue seguido por Malherbe. Por su parte, Tristan L'Hermite compuso otro con serventesio seguido de cuarteto -mismas rimas y distinta distribución. Si saltamos al siglo xıx, Baudelaire es un virtuoso de la forma, a la que retuerce sin escrúpulo: muchos de sus sonetos son octosílabos, uno de ellos con la estructura

17 El verbo cautivo. Aproximación a la poesía de Juan José Domenchina, El Colegio de México, México, 2007, p. 173. Según nos comunica la autora, la expresión es de Jorge Guillén.

18 Juan Díaz Rengifo, Arte poética española..., Juan de la Cuesta, Madrid, 1616 , p. 58. 
C-T-T-C ("L'avertisseur"), es decir, con los tercetos en medio, y otro que comienza por ellos ("Bien loin d'ici"), en lo cual fue seguido por Verlaine (Poèmes saturniens, 1866, Sagesse, Parallèlement, 1889, "Souvenir d'Hôpital", Poèmes divers) y Corbière (Les Amours jaunes, 1873), quien además escribió raros sonetos total o parcialmente anisosilábicos, con precedente también en Baudelaire, que en "Le chat" alterna los decasílabos con los octosílabos. Este autor llegó a abolir lo más característico del soneto, la oposición entre cuartetos y tercetos, en "Sur le Tasse en prison", que consta de siete pareados de alejandrinos. Poetas posteriores cultivaron el sonetillo eneasílabo (Jacques Madeleine, Charles Fuster, Jean Moréas, Th. Gautier, Louis Marsolleau), pentasílabo (Edmond Blanguernon), tetrasílabo (Jules Lemaître), hasta el bisílabo, que se da en Laforgue (con los cuartetos pareados), y el monosílabo, obra de Charles Cros, donde el verso se reduce a pura rima. Sonetos en trisílabos y en monosílabos se deben a Rimbaud, aunque no fueron conocidos hasta más tarde (Album dit "Zutique"). Muchos de estos autores están bien representados en la Anthologie des poètes français contemporains (1866-1921) de Gérard Walch, en tres volúmenes, que contó varias ediciones desde 1921. Mallarmé escribió sonetos de distintas medidas, algunos a la inglesa, con tres redondillas seguidas de pareado ("Chansons bas", "Petit air", 1-3...), y lo mismo hizo Valéry, que los tiene en hexasílabos y eneasílabos. Entre los Trente-trois sonnets composés au secret (1944), de Cassou, hay uno tetrasílabo y otro anisosilábico; los demás muestran otras anomalías.

En los sonetos de lengua española abundan los cuartetos de rima inversa en poetas como Othón, Icaza, Jaimes Freyre, Lugones, Herrera y Reissig y otros. De dos pareados los hizo Rubén Darío, y alguno anisosilábico, Arrieta ("La lámpara"). Distinta rima en los cuartetos la usan alguna vez Unamuno, Manuel y Antonio Machado, Morales, Río Sainz, Carriego, Delmira Agustini, Juana de Ibarbouru y Alfonsina Storni. Esta última, a quien se debe multitud de sonetos (incluso uno en versos decasílabos), formó todo un libro de ellos en endecasílabos blancos, lo cual acredita su fe en los catorce versos ${ }^{19}$. En el extremo contrario hay que mencionar el "Solo verdeamarillo para flauta. Llave de U”, de Herrera y Reissig, soneto con 37 palabras de $u$ tónica, entre ellas las de las 14 consonantes, que además van asonantadas en ú-a (Los maitines de la noche, 1902): "Úrsula punza

${ }^{19}$ Mascarilla y trébol, El Ateneo, Buenos Aires, 1938, 222 pp. 
la boyuna yunta; / la lujuria perfuma con su fruta...", etc. Más cercano a Quiroga y su condición de exiliado es Serrano Plaja, que, partidario de la rima pobre en los sonetos normales, compuso asimismo nueve asonantados (Versos de guerra y paz, 1945) ${ }^{20}$; y también Domenchina, que publicó tres en versos blancos (Poesías escogidas, 1939, Pasión de sombra, 1944) ${ }^{21}$, tres de cuartetos y tercetos monorrimos (" 3 de enero" y "20 de enero", de 4 rimas, y "28 de enero", de 3 rimas, Pasión de sombra) ${ }^{22}$, otro de tercetos monorrimos (Cuadernos Americanos, 27, 1944) ${ }^{23}$, y su tipo preferido: el soneto de dos rimas, que él llama diazmironiano, con precedente en Baudelaire, y de los que compuso casi un centenar (Pasión de sombra, Exul umbra, La sombra desterrada, Nueve sonetos y tres romances), algunos con palabras-rima repetidas, aparte los incluidos en El extrañado, posterior a la muerte de Quiroga. Entre ellos, y como caso límite, hay que citar los tres contiguos titulados "18 de enero. Testamento ológrafo" (Pasión de sombra), que presentan dos rimas, las mismas los tres ${ }^{24}$. De anomalías similares en Quiroga solo conocemos este soneto de serventesios asonantados en los pares y tercetos consonantes:

\section{MEDIA VOZ A MEDIANOCHE}

Para que te me duermas, desnuda, entre los brazos, besándote los ojos apagaré la luz, hasta que la mañana, a tientas, en la alcoba entre y pida a tus ojos el tono de su azul.

Mientras contra mi pecho duermes, de abajo arriba, en tu espalda, las yemas de mis dedos, sonámbulas, recorrerán el arpa de tus flexibles vértebras, el ritmo de tus sueños desgranarán en sarta.

Velador desvelado, mi oído estará atento a un suspiro; a la honda raíz de un movimiento, al fugaz batir de ala de un párpado cansado, al temblor de la palma, del hombro y la rodilla,

20 Nova, Buenos Aires, 1945 , pp. 127-135. Quiroga solo parece haber escrito un soneto asonantado, al que desvirtúan algo dos características peculiares: está compuesto por siete pareados anisosilábicos $(11+14)$, más otro de estrambote ("Pulso del instante", Boletín de la UIE, 38/39, enerofebrero de 1948, p. 6).

21 Obra poética, ed. cit., núms. 378, 483 y 484.

22 Ibid., núms. 479, 502 y 514.

${ }^{23}$ Ibid., núm. 733. En El extrañado incluye uno monorrimo (núm. 711).

24 Ibid., núms. 497-499. 
mis manos y mi boca... Al alba, en tu mejilla, pondrá mi beso, en cifra: "capital del Estado"

(Boletín de la UIE, 38/39, 1948, p. 7).

En cuanto a los sonetos de menor medida, señalaremos en primer lugar el "Sonetillo de sostenidos" incluido en La pícara Justina, II, ii, 4, 1 (1605), cuyo autor es aficionado a los experimentos métricos; en II, ii, 4, 4, hay otro, también octosílabo, pero de 12 versos, y en II, iii, 4, 1, uno endecasílabo asimismo de 12 versos. Sesenta años más tarde, Caramuel, otro gran experimentador, en el cap. VIII, artículo XIV, de su Rhythmica (1665 y 1668) se pregunta "an Sonetum minoribus versibus constare possit?” (p. 406), y su respuesta solo puede ser afirmativa, ya que para él en métrica todo es posible ${ }^{25}$. En consecuencia, ejemplifica con un sonetillo en Pentametri (= hexasílabos): "Esta triste vida...", otro en Hexametri (= heptasílabos, con endecasílabos al fin de cada estrofa): "La cýthara corriente", y dos más en Heptametri (= octosílabos): "Esta, marqués, os escribo" y "Ni dormida más despierta" ${ }^{26}$. Pero la palma del sonetillo temprano la lleva sin duda un autor de origen portugués, Manuel de Faría y Sousa, a quien Antonio Alatorre definió magistralmente como "especie de loco que se puso a sí mismo camisa de fuerza" ${ }^{27}$, porque se obligó a realizar en serio y llevándolas al extremo las cosas raras que los demás practicaron en broma o solo como curiosidad (entre ellas añadir asonancias en los versos impares del romance, algo que también atrajo a Quiroga). No nos entretendrá mucho porque su obra poética, enorme, apenas es conocida, y menos que ninguna esa Sexta parte de La fuente de Aganipe donde reunió un centenar de sonetillos, algunos de los cuales concentran sonetos o redondillas de su admirado Camões y otros de cosecha propia, seguidos de octavas, tercetos, canciones, sextinas y epigramas, siempre de arte menor. No obstante, convendrá decir algo de este libro, sobre todo por la doctrina que encierra en su prólogo. Según Faría, la poesía española y la italiana son imitaciones del portugués, con menu-

25 Cf. Antonio Alatorre, Cuatro ensayos sobre arte poética, El Colegio de México, México, 2007, pp. 50-54.

${ }^{26}$ Ioannis Caramuelis Primus Calamus, tomus II, ob oculos exhibens Rhythmicam quae Hispanicos, Italicos, Gallicos, Germanicos, $\mathcal{E}^{2} c$. Versus metitur, eosdemque concentu exornans... Editio secunda, Campaniae, ex Officina Episcopali, 1668, xlviii + 740 pp. en folio.

27 Op. cit., p. 245. 
dos cambios en la medida. Por tanto, el volver aquellas formas al octosílabo le parece un acto de justicia:

Si los italianos apropiaron a sí el número de nuestros versos (que no tenían, como se ve en Serafino), ¿por quéno apropiaremos a los nuestros las consonancias de los suyos? Yo pienso que más huuieran hecho en esto los que primero escriuieron Sonetos en España, imitando la disposición de la copla, sin despreciar el número dulce y suaue del verso natural... Aquí ofrezco los Campos Elisios que prometí en los vltimos renglones de mis Noches que imprimí el año de 624. Contienen vna centuria de sonetos desta nouedad en que hallo muchíssima armonía: ni la hallo poca en la otra de las Octauas con que descriuo los mismos Campos (o mi patria)... $\mathrm{Al}$ fin ha sido esto vna resolución de no escriuir más versos, y estos son reduzidos de los que entre mis papeles me dieron más lugar a hazello, que si salieran desde la primera idea luego con este número, más luzimiento lleuaran, assí como lleuan más trabajo, fácil de conocer, pues vengo a dezir en catorce versos de ocho sílabas lo que tenía en otros tantos de once. Consiguiendo en esto dos cosas que pretendía: la primera, quedarme sin papeles de versos. La segunda, presentar esta nouedad, que en más de dos pares de presumidos sé que al passo que ha de ser fácil el parecer poco auello hecho, ha de ser difícil el hazello. Siete partes son de Rimas. Esto se quede dicho, y las Musas en su monte, que yo me passo a otras mayores ocupaciones, o por lo menos a dexar esta (B-B4).

La confusión reina en varias cosas: la portada del libro reza Musa nueva de Manuel de Faria y Sousa. Parte sexta de sus Rimas (Madrid, Diego Flamenco, 1627). La numeración, curiosamente, comienza en el fol. 451 y termina en el 550, lo que parece indicar que esta parte continuaba otra u otras en el mismo volumen. Los reversos (o páginas pares) llevan esta cornisa: Quinta parte de la; los anversos (o páginas impares) completan la frase: Fuente de Aganipe. El libro es, así, parte quinta o sexta de algo cuyo título también varía (Campos Elisios, Musa nueva, Rimas, Fuente de Aganipe), y el autor se despide de las musas tras afirmar que las partes son siete, aunque hoy sabemos que la séptima, cuyo autógrafo se conserva en Évora, quedó inédita ${ }^{28}$, pero su mera existencia contradice el propósito de no escribir más poe-

${ }^{28}$ Cf. Arthur L.-F. Askins, "Manuel de Faria e Sousa's Fuente de Aganipe: The unprinted seventh part", Florilegium hispanicum: Medieval and Golden Age studies presented to Dorothy Clotelle Clarke, Hispanic Seminary of Medieval Studies, Madison, 1983, pp. 245-277. 
mas tras la presente ${ }^{29}$. Los sonetillos, numerados del 1 al 100, ocupan del fol. 451 al 501, y de ellos cinco están en portugués (núms. 10, 48, 60, 92 y 100). Como prueba de la "muchíssima armonía" que el autor encontraba en su novedad, copiamos en nota el soneto 67 , uno de los menos amorosos ${ }^{30}$.

La prehistoria del sonetillo es oscura y parece consistir en poligénesis. No es nada probable que Tomás de Iriarte conociese los precedentes cuando entre sus fábulas introduce una ("El burro del aceitero") que es un sonetillo octosílabo con estrambote. Los modernistas se inclinaron más por ampliar que por reducir el soneto, y su modelo fue ante todo la poesía francesa. Rubén Darío los hizo en versos de 10 ("Gaita galaica", Poema de otoño, 1910), 9 ("El soneto de trece versos", Cantos de vida y esperanza, 1905), 8 y 6 sílabas (Prosas profanas, 1896), más otro anisosilábico ("Un soneto a Cervantes", Cantos...); también Díaz Mirón tiene varios sonetos decasílabos, algunos de dos rimas (Lascas, 1901); Valle Inclán, un sonetillo eneasílabo ("Rosa de furias", El pasajero, 1920). Un poeta de quien nada sabemos, Amalio Rossi, publicó dos sonetillos octosílabos en Grecia, órgano del movimiento ultraísta en que colaboró Quiroga: "El soneto de sus ojos" (núm. 17, 20 de mayo de 1919, p. 9), y "El soneto de sus manos" (núm. 18, 10 de junio de 1919, p. 13). Salvador de Madariaga, próximo a Unamuno, publicó ocho octosílabos en La fuente serena (1927); Herrera y Reissig y Delmira Agustini los compusieron también en octosílabos, Lugones en heptasílabos, Nervo, poco amigo del soneto, uno en pentasílabos, otro con serventesios de alejandrinos y tercetos heptasílabos (La amada inmóvil, 1922); Manuel Machado, que escribió algunos en eneasílabos y octosílabos (uno de ellos con prefacio y estrambote), tiene un precioso sonetillo en trisílabos ("Vera-

${ }^{29}$ Faría vivió hasta 1649. En 1644 publicó una Nenia a la muerte de Isabel de Borbón, y al año siguiente varios poemas en la Pompa funeral de la misma reina. Aparte de eso, al menos las cuatro primeras partes de Fuente de Aganipe se reimprimieron en Madrid, por Juan Sánchez y Carlos Sánchez Bravo, entre 1644 y 1646.

30 "Pende sobre el Duero vn duro / peñasco que allí executa / arquitecturas de gruta / vestida de vn verde escuro. / Nunca ha tocado su muro / sutil ala, planta bruta: / de gotas frías no enxuta, / suda siempre cristal puro. / Desde su altura tocando / la superficie del río / en el hueco está sonando. / Profundamente sombrío, / a vn pecho está combidando / triste, y triste como el mío" (f. 484). 
no", Phoenix, 1936) ${ }^{31}$, y César Vallejo uno en monosílabos, que, por su carácter forzosamente agudo, cuentan como bisílabos ("El dolor de las cinco vocales", inédito hasta 1965). Gerardo Diego, amigo de Quiroga, buen sonetista y aficionado al esquema marótico, escribió "El soneto de catorce años" (Versos humanos, 1925), eneasílabo, cuya rima desmiente la forma inglesa, y en La sorpresa (1943) incluye varios sonetos octosílabos y heptasílabos, dos de los cuales empiezan por los tercetos ("Mi guerra" y "Viceversa"). También aquí encontramos a Domenchina, autor de un sonetillo en heptasílabos ("Poeta joven", Margen, 1933), y dos en octosílabos (Poesías escogidas, 1939, Perpetuo arraigo, 1949), aparte otros dos de El extrañado (1958) ${ }^{32}$. Antes de seguir, no estorbará recordar que la gran Antología de la poesía española e hispanoamericana (1882-1932), de Federico de Onís (Madrid, 1934), fraguada en el Centro de Estudios Históricos donde trabajó Quiroga, representa bien todos estos autores y selecciona sonetillos de al menos tres: González Prada, Villaespesa y Madariaga ${ }^{33}$.

En la historia del sonetillo vernáculo es obligado un breve excurso acerca de un vate tan olvidado hoy como leído entonces, el alpujarreño Francisco Villaespesa (1877-1936), que publicó más de cincuenta poemarios entre 1898 y 1935, en los cuales muestra también cierta afición a los experimentos métricos. Ya en La copa del rey de Thule ${ }^{34}$ figuran sonetos hexadecasílabos, junto a otros en alejandrinos. Sus primeros sonetillos, octosílabos, aparecen en Veladas de amor (1903). Los siguientes, también octosílabos, los recoge In memoriam (1904); en Tristitiae rerum ${ }^{35}$, hay uno heptasílabo. De esta medida son "Los sonetos a la her-

31 El libro Phoenix. Nuevas canciones fue terminado de imprimir por Altolaguirre en Ediciones Héroe el 25 de mayo de 1936 (tirada de 750 ejemplares en folio), es decir, menos de dos meses antes de estallar la Guerra Civil, pero sin duda hubo de circular pronto entre los poetas del grupo.

32 Ed. cit., núms. 321, 379, 619, 705 y 708.

33 Como curiosidad, recordaremos lo que dice Alatorre en el capítulo sobre consonantes forzados del delicioso libro que venimos citando: "Hubo en la revista Vuelta, de julio de 1987 a julio de 1988 (núms. 128 a 140), una pequeña y curiosa epidemia de sonetos y sonetillos de consonantes forzados...”. Sonetillos cita varios de Ulalume González de León, Severo Sarduy, García Terrés, Raúl Renán y Guillermo Fárber (Cuatro ensayos sobre arte poética, pp. 403-404).

34 Tip. El Trabajo, Madrid, 1900.

35 Pueyo, Madrid, 1906. 
mana" de Canciones del camino ${ }^{36}$, algunos con cuartetas en lugar de redondillas. El mirador de Lindaraxa ${ }^{37}$ se abre con 14 sonetillos eneasílabos; así son cinco de los incluidos en Saudades ${ }^{38}$, y el inicial de Bajo la lluvia ${ }^{39}$, mientras que El espejo encantado ${ }^{40}$ termina con sonetillos octosílabos. El primero de Los panales de oro ${ }^{41}$, de igual medida, podría bien ser el primer sonetillo inverso en castellano, es decir, que empieza con los tercetos, y termina con cuarteta y redondilla. El mismo libro contiene nueve sonetillos octosílabos, siete eneasílabos ("Motivos andaluces"), y treinta más que vuelven a los octosílabos. Palabras antiguas ${ }^{42}$ concluye con "Estrellas lejanas", donde hay seis sonetillos octosílabos. De igual medida y con cuartetas es el envío titulado "Romanza" que cierra Jardines de plata ${ }^{43}$. Un sonetillo octosílabo y cuatro eneasílabos contiene El velo de Isis ${ }^{44}$. Lámparas votivas ${ }^{45}$ agrupa 17 sonetillos octosílabos amorosos bajo el epígrafe "Suavidades para la suave", y otros 26 bajo "Rosario de amatistas". Dos asimismo octosílabos contiene Ajimeces de ensueño ${ }^{46}$, ambos con cuarteta seguida de redondilla. Nuevo experimento encontramos en Campanas pascuales ${ }^{47}$ : "Eternum pace" [ sic] acoge 21 sonetos decasílabos, amén de 14 eneasílabos titulados "A media voz". También son eneasílabos los dos de El reloj de arena ${ }^{48}$, mientras que octosílabos los tres de Baladas de cetrería ${ }^{49}$. Caracol marino ${ }^{50}$ presenta varios sonetos anisosilábicos en las secciones "Sonetos de la infancia", "Recreaciones infantiles", "Los sonetos de la adolescencia" y "Mandolinata romántica". Vasos de arcilla ${ }^{51}$ comienza con 19 sonetillos octosílabos, luego dos decasílabos.

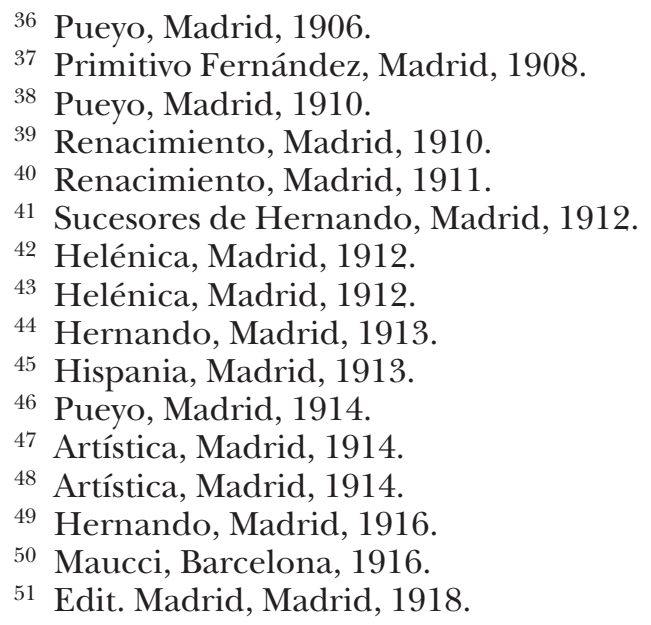


La gruta azul ${ }^{52}$ es el primer libro todo hecho de sonetillos, 34 en total, eneasílabos. El libro del mal amors ${ }^{53}$ ofrece, tras un soneto regular, 46 sonetillos hexasílabos, muchos con cuarteta inicial, a los que siguen diez octosílabos. Por último, Manos vacías ${ }^{54}$ lleva una dedicatoria que es un sonetillo octosílabo; los demás son endecasílabos. En resumen, entre los de 6 a 10 sílabas, Villaespesa habrá compuesto no menos de 330 sonetillos, lo que lo convierte en campeón de la forma, con una producción muy superior a la de Faría y Quiroga. En el plano personal, cultivó la amistad de Unamuno, Rubén Darío, Salvador Rueda, Manuel Machado, Juan Ramón Jiménez, entre otros muchos escritores, y aparte de sus numerosos poemarios, publicó hasta doce volúmenes de sus obras completas, que incluyen dramas estrenados con cierto éxito, es decir, se trata de alguien que estuvo muy presente en el panorama literario hasta la Guerra Civil ${ }^{55}$.

El anterior repaso no pretende ser exhaustivo, sino mostrar que Quiroga siguió huellas ajenas buscando la mayor flexibilidad dentro de la estrofa. Un elemento hasta ahora no mencionado indica su dependencia, directa o indirecta, de la lírica francesa. En ella, como es sabido, Clément Marot introdujo el esquema CCD EED para los tercetos, Jacques Peletier la variante EDE en el segundo, y ambas dominan desde el siglo XVI. En Morir al día, de Quiroga, hay 27 sonetos maróticos puros y 3 peleterianos, que suman un $20 \%$ del total. En La realidad reflejada, 43 maróticos y 9 peleterianos, un $41.2 \%$ del conjunto. Conviene saber que en la lírica clásica italiana y española tales fórmulas son prácticamente inexistentes, pero el modernismo las adoptó pronto, desde Rubén Darío a Rueda, Villaespesa y el joven Juan Ramón Jiménez, a quienes sigue Domenchina. Louis Aragon, que consideraba los cuartetos amurallados por su rima externa, encuentra en los tercetos así dispuestos una liberación: "De cette pensée musicalement prisonnière on s'évadera, dans les tercets, en renonçant à ce jeu pour des rimes nouvelles: et c'est ici la beauté sévère des deux vers rimant (selon la disposition marotique française), qui se suivent immediatement, pour laisser le troisième sur sa rime impaire demeurée en l'air,

52 Maucci, Barcelona, 1918.

53 Maucci, Barcelona, 1921.

54 Norma, Madrid, 1935.

55 En 1917 hizo un viaje por América que lo llevó a Venezuela, México, Santo Domingo y Brasil, donde contrajo una enfermedad de la que no llegó a reponerse. 
sans réponse jusqu'à la fin du sonnet, comme une musique errante" 56 . Huelga aclarar que cuando la rima no es la misma en ambos cuartetos (redondillas), o los sustituyen serventesios (cuartetas), no digamos en los pocos sonetos que comienzan por los tercetos o usan pareados, la supuesta dialéctica de la forma cambia radicalmente o, por usar la expresión de Aragon, la machine à penser, si lo es, funciona de otra manera; incluso en la disposición de Peletier, la rima pendiente en el v. 11 no halla su correspondencia al final del poema sino en el v. 13.

Falta aún por señalar otra modalidad en los libros de Quiroga, que es el soneto-frase, tipo 1 en la clasificación de André Gendre $^{57}$. Morir al día presenta un caso, el núm. 98 (p. 78), eneasílabo; otro podría ser el 114 (p. 86), endecasílabo. Entre los 126 sonetillos de La realidad reflejada, 27 constan de una frase, lo que supone el $21.4 \%$ del total. En la poesía del Siglo de Oro, donde los sonetos son siempre de arte mayor, no abundan los constituidos por una frase, pero se dan de vez en cuando, y naturalmente varían según la puntuación que se adopte: alguno hay en Góngora, y el caso más notable es quizá el de Pedro Espinosa "Como el triste piloto que por el mar incierto", de versos alejandrinos. En la poesía moderna escasean: Domenchina, por ejemplo, no tiene ningún soneto-frase en toda su producción. El único que se acerca es el "Madrigal bárbaro" (Perpetuo arraigo), aunque su continuidad se ve interrumpida en v. 11 por unos puntos suspensivos. La clasificación de Gendre, útil para apreciar el ajuste o el desajuste de la sintaxis con la métrica, establece además otros cuatro tipos: el 2, cuando la primera frase abarca los cuartetos y la segunda los tercetos; el 3, si los cuartetos acogen sendas frases y otra los tercetos; el 4, en que cada estrofa encierra una frase; y el 5, que reúne los no comprendidos en los anteriores.

Como hemos visto, La realidad reflejada acrecienta mucho la proporción de poemas regidos por la fórmula marótica, así como la de los sonetos-frase, respecto al libro anterior. Dicho de otra manera, mientras que en este poemario los sonetos del quinto tipo (variedades más entrecortadas) alcanzan el $82 \%$,

56 Cit. por Henri Weber, La création poétique au XVI e siècle en France, Nizet, Paris, 1955, p. 235. En el trabajo de ArAGon, que es del año anterior, parece escucharse un eco del soneto de T. Gautier que describe los cuartetos como caballeros fieramente armados y los tercetos como pajes galantes ("Les quatrains du Sonnet sont des bons chevaliers...", Poésies diverses).

57 A. GENDre, Évolution du sonnet français, PUF, Paris, 1996, p. 20. 
en el siguiente el porcentaje de estos sonetos a los que, para entendernos, llamaremos díscolos se reduce a poco más de la mitad, síntoma del menor forcejeo con la sintaxis que exige el verso breve; téngase en cuenta que en Morir al día, además de 127 sonetos endecasílabos, hay 18 en alejandrinos. Si a eso se añade que La realidad reflejada es el único libro compuesto por sonetillos, que sepamos, desde La gruta azul, de Villaespesa (1918), vemos que se trata de un sonetario -valga el neologismo- excepcional por su novedad solo en el plano de la forma. Una forma que también presenta algo curioso. En Morir al día hay sonetos de los tipos 1 y 2 , donde la categoría se ve algo empañada por una puntuación ligera (dos puntos, o punto y coma) que no está claro si rompe la frase o suelda sus partes; la fluencia se puede también ver interrumpida por una frase parentética aseverativa o interrogativa. De igual manera, cuando el poema comienza por una invocación, no es seguro si el vocativo inicial supone una frase distinta de la que sigue. Veamos algún ejemplo:

\title{
TANTO SOÑAR, TANTO CORRER
}

\author{
¡Tanto soñar con renacer \\ a cada vuelta de la vida \\ y es no más para conocer, \\ por una vez más repetida, \\ la limitada y desabrida \\ experiencia -mañana, hoy, ayer, \\ idénticamente aburrida- \\ que encuentra el hijo de mujer \\ a lo largo de los senderos \\ recorridos con pies ligeros \\ entre una sombra que le acosa \\ y otra que huye ante su pisada \\ hasta que en la última posada \\ el lecho cambia por la fosa!
}

(Morir al día, p. 78).

Los componentes de este sonetillo apuntan a la lírica francesa: las cuartetas, el esquema marótico en los tercetos, y sobre todo el eneasílabo, cuya rareza en castellano explica el fallo de v. 6, decasílabo, que provoca el único sonnet boiteux de Quiroga. En cualquier caso, ahora nos interesa destacar lo forzado de la frase exclamativa, que se prolonga y bifurca en complementos 
circunstanciales y subordinadas. He aquí otro ejemplo, de $L a$ realidad reflejada (p. 110):

¿Qué cosa más complicada, un hombre y una mujer y, entre los dos, su querer como una sierra abrasada que cada cual, por su lado, escala para encontrar -brújula de su acezar y espejismo desvelado-

la figura de su sed y la sed de su figura, real y a un tiempo soñada, sirena presa en la red que teje la calentura de un ansia de todo o nada!

Dejando a un lado el hecho de comenzar con redondillas y recuperar la rima $a$ en los tercetos, el poema es también una frase exclamativa, dividida en dos grupos de seis versos que dejan en medio la imagen parentética de vv. 7-8, lo que, junto a la octosilabia, le presta mayor naturalidad: frase nominal que se refuerza sin violencia con dos oraciones de relativo. Si observamos su estructura, veremos que la primera redondilla casi se basta a sí misma, al plantear un asunto que luego se desarrolla. Esto, frecuente en Quiroga, admite diversas plasmaciones gráficas, por ejemplo, una puntuación débil, como se ve en un sonetillo algo posterior, excluido de La realidad reflejada:

Ala de nubes, en vuelo sereno, redondo, augusto, con que al paisaje da el cielo su punto de emoción justo:

colgada en su marco, enfrente de este eremita de hotel, baña el muro y su papel de una medialuz caliente que reposa la mirada con su callado latido, como la melancolía familiar y decantada de un sonreír desvaído en una fotografía. (BUIE, IV, núms. 30/32, mayo-julio de 1947, p. 7). 
Todo aquí fluye suavemente, a pesar de la nueva rima de la segunda estrofa, que es una redondilla, opuesta a la cuarteta inicial. El tema se encierra en los primeros cuatro versos, mientras que el resto del soneto es el rema; de ahí la barrera menor de los dos puntos en v. 4. Esta va a ser la fórmula preferida de Quiroga, un tipo intermedio entre los dos primeros. A veces el tema es un solo verso: "Pesada lluvia estival: / empañado de calina / el cielo...", etc. (p. 37), o una sola palabra: "Frontera: un amanecer / entre sabido y soñado...", etc. (p. 27). Pero la puntuación es engañosa: "Otoño, roja bocina / del ocaso..." (p. 104) comienza otro soneto-frase en la que se define el otoño. El término inicial podría ir seguido de dos puntos, en lugar de coma, incluso de punto y seguido, como sucede en el soneto contiguo: "Noviembre. La niebla, reina / de las mañanitas frías..." (p. 105), donde el punto solo es la linde mínima entre lo definido y la definición, y por tanto no impide considerarlo soneto-frase. También el soneto "Pies, frescos peces del lecho" (p. 121) pinta los pies, con la aposición que sigue a la coma y se ramifica hasta el final.

Si el tipo 2 comprende sonetos que reparten equitativamente la sintaxis entre los cuartetos y los tercetos, hay hasta 11 en Morir al día, mientras que no serán más de media docena los que cumplen el requisito en La realidad reflejada. En cambio, en este libro siguen siendo numerosos los del tipo intermedio, en los que la división no es equitativa ni se adapta a la pauta estrófica. Así, en "Se ríe la Reina Mora” (p. 91), “¿Cuál es el espejo y cuál...?” (p. 155), una frase ocupa los dos primeros versos, la otra los demás; lo mismo podría decirse de "Aquí se acaba el camino" (p. 159), porque los puntos que separan las tres frases iniciales, en dos versos, en realidad forman una sola asindética. En “¡El auto en la carretera...!” (p. 51), "Cantaré, cuando el tren corra” (p. 55), “¡Gallos de la madrugada...!" (p. 70), "Te miro de arriba abajo" (p. 116), "Pura, tanto, que es, desnuda" (p. 120), "Tu peso aguarda, sirena" (p. 125), una frase llena la estrofa inicial y la otra el resto; es la fórmula más frecuente. Casos extremos son "¿Cómo, si ajena ya y lejos...?” (p. 151), cuya pregunta inicial ocupa seis versos, y después del séptimo viene otro interrogante que termina en v. 14. Y "Escaparate, vitrina" (p. 44), donde la primera frase llega hasta el v. 13, dejando el 14 para la segunda. Incluso en Morir al día, el soneto titulado "El pescador de estrellas" (p. 108), asimismo dividido en dos frases, de las que la primera ocupa la redondilla inicial y 
la mitad del verso siguiente, entraría en este tipo mejor que en el quinto, a no ser que se considere más relevante el ajuste del verso a la sintaxis.

De lo dicho se desprende una conclusión que enlaza con nuestro comienzo. El neoclasicismo de Quiroga es indudable y de buena ley. Aunque en sus años mozos coqueteó con las vanguardias, vio pronto claro que aquel camino no era el suyo, como tampoco un academicismo frío y resignado a la imitación. Las formas artísticas, incluso las más trilladas, pueden dar mucho juego siempre que se manejen debidamente sus resortes. Quiroga se percató de que en la forma soneto, ya expandida hacia dentro y hacia fuera por los predecesores -como lo fue la forma sonata en la música-, era posible plasmar cualquier mundo poético, y en especial, por alguna razón desconocida, la paratopía propia del exilio, que al mismo tiempo, y al otro lado del Atlántico, iba construyendo otro poeta con elementos muy similares: Juan José Domenchina. La diferencia, obvia, es que Domenchina se volcó hacia dentro, para hurgar sin descanso en su dolor de desterrado, mientras que Quiroga, primero, recuerda personas y lugares, y en seguida se fija en lo que tiene a su alrededor: nuevo país, nuevos amigos, nuevos amores, habla incluso de "Salvación por el olvido" (Morir al día, p. 205). Bien claro lo deja su sonetillo "Propósito", de rima anómala, escrito poco después de terminar la ocupación de Francia por los alemanes:

El pan nuestro de cada día y el necesario y cotidiano sinsabor. La frente en la mano -si en el resol posmeridiano

que el llegar de la noche enfría y adelgaza, flota el vilano de una vaga melancolía. Pero, en los ojos, la alegría...

Entre el esfuerzo confiado y el amargor del desaliento, sé como la hierba en el prado:

el pie la chafa, el sol la tuesta, y ella, cantando, alza en el viento su voluntad de ser enhiesta

(París, 21 octubre de 1944, Morir al día, p. 89). 
El sonetillo, aunque algo áspero, es muy expresivo: su primer verso, frase hecha procedente del Padrenuestro en versión antigua $^{58}$, permite asimilar el pan al sinsabor, no menos cotidiano y necesario. La única concesión a la tristeza ("vilano de una vaga melancolía") es la frente en la mano (cf. el verso de Alfonso Reyes: "la mano acudió a la frente / queriéndola sosegar", Romances del Río de Enero, 1932). Pero destaca la alegría en los ojos, impulso que lleva a la exhortación de los tercetos, cuyo símil sorprende en un poeta enfermo, separado de su tierra y de su gente.

Entre los dos libros, Quiroga publicó varios sonetillos que, con pocos cambios, fueron a parar a La realidad reflejada. Aparte alguno de circunstancias, dejó también fuera media docena, que figuran agrupados con otros dos poemas de distinta métrica bajo el título "Fábrica de realidad". De los seis solo el quinto pasó el filtro y aparece en el volumen ("Ese jinete soy yo", p. 153). El último servirá de colofón a nuestro estudio, porque, al definir la poesía en forma tan inesperada, muestra un caso más de hombre que, en las peores circunstancias, se aferra a su lengua, única tabla salvadora:

\author{
Poesía. La poesía: \\ telar en que cada hebra \\ se anima con la culebra \\ de fuego que el sol le envía, \\ orden del alba; telar \\ a que, como a escolanía, \\ va la creación, con el día, \\ para aprender a cantar. \\ A cantar, y el canto a ser, \\ en tejer y destejer, \\ cifra de profundidad, \\ secreto de cada día, \\ eternidad -poesía, \\ fábrica de realidad!
}

(BUIE, IV, núms. 30/32, mayo-julio de 1947, p. 7).

Antonio Carreira

58 "El pan nuestro / de cada día / danos lo oy". Así figura el Pater Noster en la Doctrina Christiana, con vna exposición breue, compuesta por el maestro Hierónymo de Ripalda de la Compañía de Iesús (Burgos, Philippe de Iunta, 1591 , f. $11 v^{\circ}$ ), que estuvo vigente hasta finales del s. Xx. 